\title{
Defects in flagellin glycosylation affect the virulence of Pseudomonas syringae pv. tabaci 6605
}

\begin{abstract}
Correspondence
Yuki Ichinose

yuki@cc.okayama-u.ac.jp
\end{abstract}

Received 8 May 2009

Revised 19 September 2009

Accepted 2 October 2009
Fumiko Taguchi, ${ }^{1}$ Masanobu Yamamoto, ${ }^{2}$ Mayumi Ohnishi-Kameyama, ${ }^{2}$ Masako Iwaki, ${ }^{1}$ Mitsuru Yoshida, ${ }^{2}$ Tadashi Ishii, ${ }^{3}$ Tomoyuki Konishi ${ }^{3}$ and Yuki Ichinose ${ }^{1}$

${ }^{1}$ Graduate School of Natural Science and Technology, Okayama University, Tsushima-naka 1-1-1,
Okayama 700-8530 Japan
${ }^{2}$ National Food Research Institute, 2-1-12 Kannondai, Tsukuba, Ibaraki 305-8642, Japan
${ }^{3}$ Forestry and Forest Products Research Institute, 1 Matsunosato, Tsukuba, Ibaraki 305-8687, Japan

Flagellar motility and its glycosylation are indispensable for the virulence of Pseudomonas syringae pv. tabaci 6605 . Six serine residues of the flagellin protein at positions $143,164,176$, 183,193 and 201 are glycosylated, and the glycan structure at 201 was determined to consist of a trisaccharide of two L-rhamnosyl residues and a modified 4-amino-4,6-dideoxyglucosyl (viosamine) residue. To investigate the glycan structures attached to the other serine residues and to identify the glycans important for virulence, Ser/Ala-substituted mutants were generated. Six mutant strains that each retained a single glycosylated serine residue were generated by replacing five of the six serine residues with alanine residues. MALDI-TOF mass analysis of flagellin proteins revealed that the major component of each glycan was a trisaccharide basically similar to that at position 201, but with heterogeneity in glycoform distribution. Swarming motility and amounts of acylhomoserine lactones (AHLs) as quorum-sensing signal molecules were significantly reduced, especially in the S143-5S/A, S164-5S/A and S201-5S/A mutants, whereas tolerance to antibiotics was increased in these three mutants. All the mutants showed lower ability to cause disease on host tobacco plants. These results supported our previous finding that glycosylation of the most externally located sites on the surface of the flagellin molecule, such as S176 and S183, is required for virulence in $P$. syringae pv. tabaci 6605. Furthermore, it is speculated that flagellum-dependent motility might be correlated with quorum sensing and antibiotic resistance.

\section{INTRODUCTION}

Pseudomonas syringae pv. tabaci 6605 is a Gram-negative phytopathogenic bacterium and the causal agent of wildfire disease on tobacco plants (Ichinose et al., 2003; Taguchi et al., 2006b). This bacterium has several flagella at the cell pole. Previous results in our laboratory revealed that flagella are indispensable for virulence in host tobacco infection, and that a major component of flagellum, the flagellin protein, which is a fliC gene product, acts as the potential elicitor of the defence response in plants (Ichinose et al., 2003; Shimizu et al., 2003; Taguchi et al., 2003a, b, 2006b). It was also revealed that glycosylation of flagellin is catalysed by two glycosyltransferases named FGT1 and FGT2, whose genes are located in a flagellin glycosylation island, and that $\Delta f g t 1$ and $\Delta f g t 2$ mutants produced non-glycosylated and

Abbreviations: EPS, extracellular polysaccharide; HHL, N-hexanoyl-Lhomoserine lactone; $\mathrm{OHHL}, \mathrm{N}$-(3-oxohexanoyl)-L-homoserine lactone.

A supplementary figure is available with the online version of this paper. partially glycosylated flagellins, respectively (Taguchi et al., 2006a; Takeuchi et al., 2003, 2007). The HPLC analysis of digested fragments of flagellin protein suggested that the six serine residues at positions 143, 164, 176, 183, 193 and 201 are glycosylated (Taguchi et al., 2006b). Characterization by MALDI-TOF mass analysis of each site-replaced Ser/Ala mutant confirmed that the molecular mass of the glycan at each glycosylated position was about $540 \mathrm{Da}$. The six Ser/Ala-substituted (S143A, S164A, S176A, S183A, S193A, and S201A) mutants had lower ability to adhere to hydrophobic surfaces, lower swarming motility, and lower virulence on the host tobacco plant, indicating that glycosylation of flagellin in this bacterium is required for virulence (Taguchi et al., 2006b). Among the single Ser/Ala-substituted mutants, the effect of the Ala substitution in S176A and S183A was strongest, suggesting that the glycosylated positions on the putative surface-exposed region are important determinants of flagella-mediated virulence (Taguchi et al., 2006b, 2008). 
The glycan structure at serine 201 of flagellin proteins from $P$. syringae pv. tabaci 6605 and $P$. syringae pv. glycinea race 4 has been identified (Takeuchi et al., 2007). Analysis of the sugar composition, mass spectrometry and NMR spectroscopy revealed that a trisaccharide composed of two rhamnosyl (Rha) residues and one modified 4-amino4,6-dideoxyglucosyl (viosamine) residue was attached to serine 201 of both pathovars. Interestingly, the glycans of the flagellin from $P$. syringae pv. tabaci 6605 possess only L-rhamnose (L-Rha), whereas the $P$. syringae pv. glycinea race 4 glycan contains also D-Rha at a ratio of $4: 1$ (Takeuchi et al., 2007). Because the deduced amino acid sequences of flagellin from these pathovars are identical, post-translational modification of glycosyl residues, especially in the different ratios of $\mathrm{D}$ and L configurations, might be important for the virulence and determination of host specificity.

In this study, to elucidate the glycan structures attached to other glycosylation sites and to determine the most important position for virulence, a series of six Ser/Alasubstituted mutants (S143-5S/A, S164-5S/A, S176-5S/A, S183-5S/A, S193-5S/A and S201-5S/A) was generated in $P$. syringae pv. tabaci 6605 by site-directed mutagenesis. Each mutant strain retained one of the six glycosylated serine residues. Using these glycosylation-defective mutant strains, detailed MS analysis was used to identify the glycan structure attached to each glycosylation site, and its correlation with determinants of flagellar motility and virulence, such as the production of $\mathrm{N}$-acylhomoserine lactones (AHLs) and antibiotic resistance, was investigated.

\section{METHODS}

Bacterial strains and growth conditions. All bacterial strains used in this study are listed in Table 1. Pseudomonas syringae pv. tabaci 6605 strains were maintained as described previously (Taguchi et al., 2006b). Escherichia coli strains were grown at $37{ }^{\circ} \mathrm{C}$ in Luria-Bertani (LB) medium. Chromobacterium violaceum $\mathrm{CV} 026$ was maintained at $30{ }^{\circ} \mathrm{C}$ in LB with kanamycin at a final concentration of $50 \mu \mathrm{g} \mathrm{ml}^{-1}$ (McClean et al., 1997). The culture volume of each strain was $3 \mathrm{ml}$, and shaking conditions were 130 r.p.m. for E. coli and 110 r.p.m. for P. syringae pv. tabaci 6605.

Plant material, inoculation procedure, and bacterial growth. Tobacco plants (Nicotiana tabacum 'Xanthi NC') were grown at $25{ }^{\circ} \mathrm{C}$ with a $12 \mathrm{~h}$ photoperiod. For dip-inoculation, bacterial strains were suspended in $10 \mathrm{mM} \mathrm{MgSO}_{4}$ and $0.02 \%$ Silwet L77 (OSI Specialties) at a density of $6 \times 10^{8}$ c.f.u. $\mathrm{ml}^{-1}$, and detached tobacco leaves (three leaves for each strain) were soaked in the suspension for $20 \mathrm{~min}$. The inoculated leaves were incubated under conditions of $85 \%$ humidity in a growth cabinet for 10 days at $23{ }^{\circ} \mathrm{C}$ with an $18 \mathrm{~h}$ photoperiod. To maintain the turgidity of the detached leaves, water was supplied to the cut petiole.

To examine the bacterial growth, five leaf discs ( $5 \mathrm{~mm}$ diameter) were punched from tobacco leaves and soaked for $20 \mathrm{~min}$ in a suspension of bacteria in $10 \mathrm{mM} \mathrm{MgSO}_{4}$ and $0.02 \%$ Silwet at a density of $6 \times 10^{8}$ c.f.u. $\mathrm{ml}^{-1}$. At 3 or 6 days after inoculation, the discs were soaked in $15 \% \mathrm{H}_{2} \mathrm{O}_{2}$ for $1 \mathrm{~min}$ to sterilize the leaf surface, washed with sterile distilled water, and ground in a mortar. Serially diluted samples $(10 \mu \mathrm{l})$ in $10 \mathrm{mM} \mathrm{MgSO}_{4}$ were spotted on $\mathrm{KB}$ plates; the numbers of colonies that appeared after $48 \mathrm{~h}$ incubation at $27{ }^{\circ} \mathrm{C}$ were counted, and the bacterial populations were calculated.

Construction of mutants. To construct the six glycosylationdefective mutants, a Quik Change XL site-directed mutagenesis kit was employed as described previously (Taguchi et al., 2006b). Each

Table 1. Bacterial strains and plasmids

$A m p^{r}$, ampicillin resistant; $\mathrm{Km}^{\mathrm{r}}$, kanamycin-resistant; $\mathrm{Nal}^{\mathrm{r}}$, nalidixic acid resistant.

\begin{tabular}{|c|c|c|}
\hline Strain or plasmid & Relevant characteristics & Reference or source \\
\hline $\mathrm{DH} 5 \alpha$ & 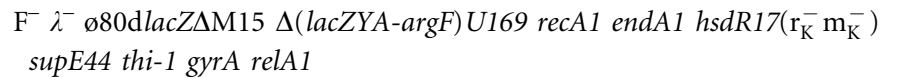 & Takara \\
\hline S17-1 & thi pro $h s d R$ hsdR $h s d M^{+} \operatorname{rec} A(c h r:: \mathrm{RP} 4-2-\mathrm{Tc}:: \mathrm{Mu}-\mathrm{Km}:: \mathrm{Tn} 7)$ & Schäfer et al. (1994) \\
\hline \multicolumn{3}{|c|}{ P. syringae pv. tabaci } \\
\hline Isolate 6605 & Wild-type isolated from tobacco, $\mathrm{Nal}^{\mathrm{r}}$ & Shimizu et al. (2003) \\
\hline $6605-\mathrm{d} 1$ & Isolate $6605 \Delta f g t 1, \mathrm{Nal}^{\mathrm{r}}$ & Taguchi et al. (2006b) \\
\hline 6605-S143-5S/A & Isolate $6605 \mathrm{~S} 164 \mathrm{~A}, \mathrm{~S} 176 \mathrm{~A}, \mathrm{~S} 183 \mathrm{~A}, \mathrm{~S} 193 \mathrm{~A}, \mathrm{~S} 201 \mathrm{~A} \mathrm{Nal}{ }^{\mathrm{r}}$ & This study \\
\hline 6605-S164-5S/A & Isolate $6605 \mathrm{~S} 143 \mathrm{~A}, \mathrm{~S} 176 \mathrm{~A}, \mathrm{~S} 183 \mathrm{~A}, \mathrm{~S} 193 \mathrm{~A}, \mathrm{~S} 201 \mathrm{~A} \mathrm{Nal}{ }^{\mathrm{r}}$ & This study \\
\hline 6605-S176-5S/A & Isolate $6605 \mathrm{~S} 143 \mathrm{~A}, \mathrm{~S} 164 \mathrm{~A}, \mathrm{~S} 183 \mathrm{~A}, \mathrm{~S} 193 \mathrm{~A}, \mathrm{~S} 201 \mathrm{~A} \mathrm{Nal}{ }^{\mathrm{r}}$ & This study \\
\hline 6605-S183-5S/A & Isolate $6605 \mathrm{~S} 143 \mathrm{~A}, \mathrm{~S} 164 \mathrm{~A}, \mathrm{~S} 176 \mathrm{~A}, \mathrm{~S} 193 \mathrm{~A}, \mathrm{~S} 201 \mathrm{~A} \mathrm{Nal}{ }^{\mathrm{r}}$ & This study \\
\hline 6605-S193-5S/A & Isolate $6605 \mathrm{~S} 143 \mathrm{~A}, \mathrm{~S} 164 \mathrm{~A}, \mathrm{~S} 176 \mathrm{~A}, \mathrm{~S} 183 \mathrm{~A}, \mathrm{~S} 201 \mathrm{~A} \mathrm{Nal}{ }^{\mathrm{r}}$ & This study \\
\hline \multicolumn{3}{|c|}{ - } \\
\hline pGEM-TEasy & $3.015 \mathrm{~kb}$ cloning vector for PCR product; $\mathrm{Amp}^{\mathrm{r}}$ & Promega \\
\hline pK18mobSacB & Small mobilizable vector, $\mathrm{Km}^{\mathrm{r}}$, sucrose sensitive $(\operatorname{sacB})$ & Schäfer et al. (1994) \\
\hline
\end{tabular}


mutation was confirmed by sequencing, and mutated DNA fragments were cloned into the mobilizable cloning vector $\mathrm{pK} 18 \mathrm{mobsacB}$ via a BamHI site (Schäfer et al., 1994). The resulting plasmids were introduced into E. coli S17-1 and integrated into the wild-type (WT) $P$. syringae pv. tabaci 6605 by conjugation and homologous recombination. Nucleotide sequences of each mutant strain were confirmed by direct sequencing of bacterial genomic DNA by PCR.

Motility assay. Bacteria cultured overnight in LB medium containing $10 \mathrm{mM} \mathrm{MgCl}_{2}$ at $25{ }^{\circ} \mathrm{C}$ were resuspended in $10 \mathrm{mM} \mathrm{MgSO}_{4}$ and adjusted to an $\mathrm{OD}_{600}$ of 0.3 . Aliquots $(3 \mu \mathrm{l})$ were inoculated into the centre of MMMF (50 mM potassium phosphate buffer, $7.6 \mathrm{mM}$ $\left(\mathrm{NH}_{4}\right)_{2} \mathrm{SO}_{4}, 1.7 \mathrm{mM} \mathrm{MgCl}_{2}$, and $1.7 \mathrm{mM} \mathrm{NaCl}, \mathrm{pH}$ 5.7, containing $10 \mathrm{mM}$ of mannitol and fructose) plates with $0.25 \%$ agar for the swimming assay (Taguchi et al., 2006b) or SWM (0.5\% peptone, $0.3 \%$ yeast extract; Difco) plates with $0.45 \%$ agar for the swarming assay (Kinscherf \& Willis, 1999). The diameters of the swimming or swarming areas were compared after incubation for $48 \mathrm{~h}$ at $25^{\circ} \mathrm{C}$ or for $24 \mathrm{~h}$ at $27^{\circ} \mathrm{C}$, respectively.

Tolerance to antibiotics. Each strain was grown for $24 \mathrm{~h}$ in $\mathrm{KB}$ liquid medium, and $3 \mathrm{ml}$ bacterial suspension was overlaid after dilution with $15 \mathrm{ml} \mathrm{KB}$ medium with $0.5 \%$ agar. A paper disc (Whatman $3 \mathrm{MM}$ paper) containing $10 \mu \mathrm{l}$ of antibiotic solution (chloramphenicol at $17.5 \mu \mathrm{g} \mathrm{l}^{-1}$ and spectinomycin at $25 \mu \mathrm{g} \mu \mathrm{l}^{-1}$ ) was put on the bacteria-containing plate. The diameter of the growth inhibition zone was measured after incubation for $24 \mathrm{~h}$ at $27^{\circ} \mathrm{C}$ (Taguchi et al., 2006a).

Drop-collapsing test for biosurfactant detection. Each bacterial strain was grown on a KB plate containing $1.5 \%$ agar for $48 \mathrm{~h}$ at $27{ }^{\circ} \mathrm{C}$, scraped off, and suspended in $10 \mathrm{mM} \mathrm{MgSO}_{4}$. After adjustment to an $\mathrm{OD}_{600}$ of $1.0,10 \mu \mathrm{l}$ aliquots of the supernatant were spotted onto Parafilm to determine the surface tension (Taguchi et al., 2006b).

Quantitative analysis of extracellular polysaccharide (EPS). Each bacterial strain was grown on a KB plate containing $1.5 \%$ agar for $48 \mathrm{~h}$ at $27{ }^{\circ} \mathrm{C}$. The detailed procedure was described in previous papers (Keith \& Bender, 1999; Taguchi et al., 2006b). Quantification of EPS was carried out by the phenol/sulfate method (Hodge \& Hofreiter, 1962). The protein concentration of each sample was determined by a Bradford protein assay (Bio-Rad protein assay). Total EPS was calculated as a relative value per total cellular protein.

Detection of acylhomoserine lactones (AHLs). Bacterial strains were grown in $\mathrm{LB}$ medium with $10 \mathrm{mM} \mathrm{MgCl} 2$ for $24 \mathrm{~h}$ at $25{ }^{\circ} \mathrm{C}$. AHLs were extracted with an equal volume of ethyl acetate (Shaw et al., 1997; Taguchi et al., 2006a). The 500-fold-concentrated samples were applied to a $\mathrm{C}_{18}$ reverse-phase TLC plate, and AHLs were detected with $C$. violaceum $\mathrm{CV} 026$ as the biosensor strain. For quantification of AHLs, the area of violet spots visualized by the induction of violacein production was calculated using $N$-hexanoyl-Lhomoserine lactone (HHL) and $N$-(3-oxohexanoyl)-L-homoserine lactone (OHHL) as the standards.

Flagellin preparation. The procedure for flagellin purification from the WT and each mutant strain has been described (Taguchi et al., 2006b).

RNA preparation and semiquantitative RT-PCR. Each strain was grown in $\mathrm{LB}$ with $10 \mathrm{mM} \mathrm{MgCl} 2$ at $27{ }^{\circ} \mathrm{C}$ to an $\mathrm{OD}_{600}$ of 0.3 and further incubated in MMMF for $1 \mathrm{~h}$. Then total RNA was extracted using a High Pure RNA Isolation kit (Roche) according to the manufacturer's instructions. Two micrograms of total RNA was used for semiquantitative RT-PCR analysis (Higashi et al., 2008). Specific primer sets, MexF-F (5'-TACAGCGAGCCCAGATAAAC- $3^{\prime}$ ) and
MexF-R (5'-GAAGCGTACATGGCGATCTT-3'), TolC-F (5' -CGTTTGTCGTAATCGCTGAA- $\left.3^{\prime}\right)$ and TolC-R ( $5^{\prime}$-AAACTGCCTGCTATCGCCAA- $3^{\prime}$ ), were designed based on the registered sequences of P. syringae pv. phaseolicola 1448A (accession number NC_005773). PCR was performed with one denaturation cycle of 2 min at $95{ }^{\circ} \mathrm{C}$ and 32 cycles of $30 \mathrm{~s}$ at $95{ }^{\circ} \mathrm{C}, 30 \mathrm{~s}$ at $52{ }^{\circ} \mathrm{C}$, and $40 \mathrm{~s}$ at $72{ }^{\circ} \mathrm{C}$. Ten microlitres of the PCR product was loaded onto $2 \%$ agarose gel. To confirm the mRNA-derived PCR amplification, the RT-PCR was performed without AMV RTase as a negative control.

Mass spectrometry of flagellin proteins. Each purified flagellin from the WT and S/A-substituted mutants was digested with trypsin (proteomics grade, Sigma-Aldrich) at $37{ }^{\circ} \mathrm{C}$ for $18 \mathrm{~h}$ in $10 \mathrm{mM}$ Tris/ $\mathrm{HCl}$ buffer $(\mathrm{pH} 8.0)$. The peptide mixture solution obtained was subjected to solid-phase extraction (ZipTip C4 pipette tips, Millipore) and was eluted with $50 \%$ acetonitrile in $0.1 \%$ trifluoroacetic acid (TFA) after washing with MilliQ water (Millipore). The solution was mixed with a matrix solution $\left(10 \mathrm{mg} \mathrm{ml}^{-1}\right)$ of sinapinic acid (Bruker Daltonics) in $30 \%$ acetonitrile in $0.1 \%$ TFA or 2,5-dihydroxybenzoic acid (Bruker Daltonics) in $20 \%$ ethanol, followed by application of the mixture to a MALDI-TOF mass target plate. MALDI-TOF mass spectra were recorded on a Reflex II instrument (Bruker Daltonik) in the positive-ion mode by summing at least 100 shots of a $337 \mathrm{~nm}$ nitrogen laser with an acceleration voltage of $20 \mathrm{kV}$. The mass spectrometer was calibrated prior to measurements using commercially available standard proteins (a mixture of insulin, ubiquitin I, cytochrome $c$ and myoglobin; Bruker Daltonics) covering the 5000 to $17500 \mathrm{~m} / \mathrm{z}$ range.

Statistical analysis. The results of the motility assay, EPS assay, TLC assay for AHLs, bacterial population measurement, and growth inhibition assay with antibiotics are expressed as means \pm SD. Comparisons between the quantitative measurements of the WT and each mutant were performed by the two-tailed $t$-test. $P<0.05$ was considered statistically significant.

\section{RESULTS}

\section{Construction of site-directed glycosylation- defective mutants}

Previously, we confirmed the presence of glycosylated residues in flagellin (positions 143, 164, 176, 183, 193 and 201) and the structure of the glycan at serine 201 (S201) was determined (Taguchi et al., 2006b, 2007). To analyse the structure of the flagellin glycans attached to the other five glycosylated residues, a series of six Ser/Ala-substituted mutants (S143-5S/A, S164-5S/A, S176-5S/A, S183-5S/A, S193-5S/A and S201-5S/A) was generated using sitedirected mutagenesis, conjugation and homologous recombination. The mutations were confirmed by DNA sequencing, and the reduction of the molecular mass of flagellin from all glycosylation defective mutants was confirmed by SDS-PAGE (Fig. 1A).

\section{Mass spectrometry of flagellin from glycosylation- defective mutants}

Mass differences between the WT and each of the five Ser/ Ala-substituted mutant flagellins were analysed more precisely by MALDI-TOF mass spectrometry after tryptic digestion. Enzymic hydrolysis of the WT flagellin gave a 
(A)

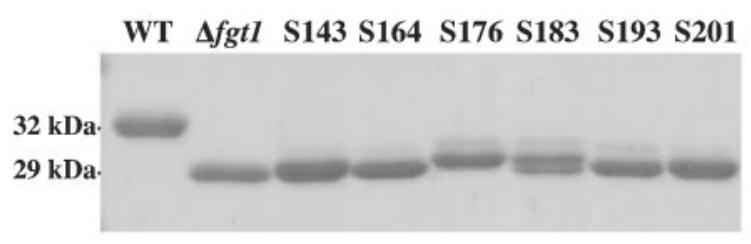

(B)

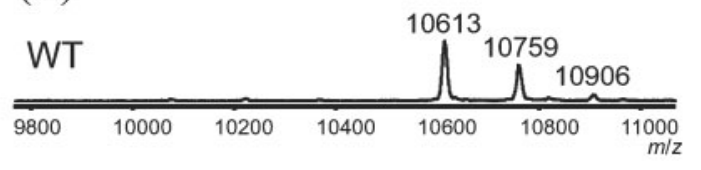

(C)
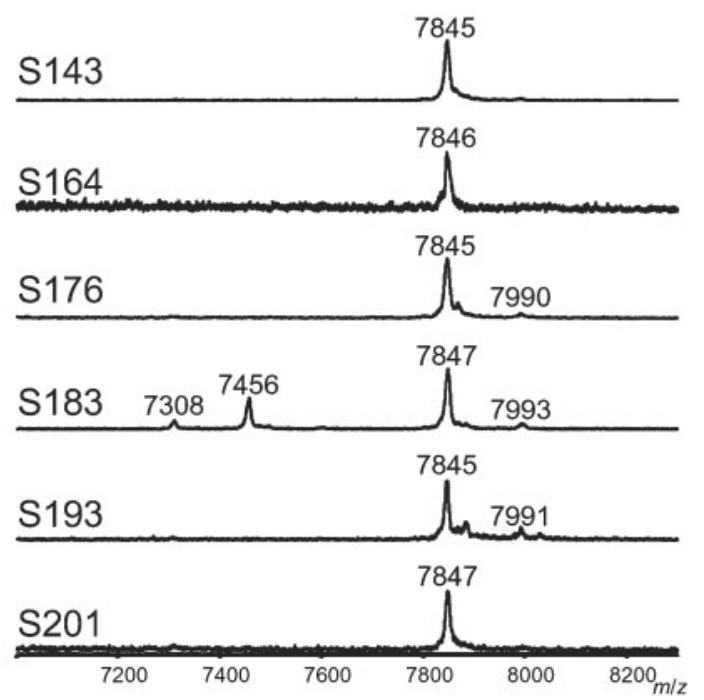

Fig. 1. SDS-PAGE (A) and MALDI-TOF mass spectra of tryptic digested peptides $(136 \mathrm{~N}-210 \mathrm{R})$ of flagellin proteins from the WT (B) and glycosylation-defective mutants (C). $\Delta f g t 1, \mathrm{~S} 143, \mathrm{~S} 164$, $\mathrm{S} 176, \mathrm{~S} 183, \mathrm{~S} 193$ and $\mathrm{S} 201$ indicate the $\Delta f g t 1, \mathrm{~S} 143-5 \mathrm{~S} / \mathrm{A}$, S164-5S/A, S176-5S/A, S183-5S/A, S193-5S/A and S201-5S/ A (S201) mutants, respectively. Peaks observed around the $[\mathrm{M}+\mathrm{H}]^{+}$peak were $[\mathrm{M}+\mathrm{Na}]^{+}$and $[\mathrm{M}+\mathrm{K}]^{+}$.

glycopeptide $136 \mathrm{~N}-210 \mathrm{R}$ including all six glycosylated serine residues. The protonated ion $[\mathrm{M}+\mathrm{H}]^{+}$was observed at $\mathrm{m} / z 10610$ in good agreement with the theoretical value of 10613.4 for the peptide $136 \mathrm{~N}-210 \mathrm{R}$ (7387.0) with six flagellin glycan chains $(6 \times 537.5)$ (Fig. 1B). Here, the flagellin glycan chain was regarded as a trisaccharide consisting of two rhamnose residues and one modified viosamine residue [ $\beta$-D-Quip4N(3-OH-1-oxo-Bu)2Me], which was identified as the glycan on 201S (Takeuchi et al., 2007). The other two peaks observed in the higher mass region corresponded to glycopeptides including one and two more rhamnose residues because the mass differences from $[\mathrm{M}+\mathrm{H}]^{+}$at $m / z 10613$ were 146 and
293, respectively. In contrast to the WT flagellin, the series of five Ser/Ala-substituted mutant flagellins showed protonated ions at around $m / z 7845$ (Fig. 1C). This value corresponded to the total molecular masses of the five Ser/ Ala-substituted peptides without glycan modifications (7308.0 Da) and the glycan chain (537.5 Da). The results revealed that all five Ser/Ala-substituted mutant flagellins each had only one flagellin glycan of 537-539 Da, and that the glycan mass was similar to that of serine 201, $538 \mathrm{Da}$. However these molecular masses showed some heterogeneity. We detected minor peaks, especially in the S183-5S/A mutant. The peaks of the S183-5S/A mutant observed at $\mathrm{m} /$ $z 7308$ and $\mathrm{m} / z 7456$ indicate the molecular masses of flagellin protein without post-translational modification and with attachment of only a single rhamnose residue, respectively. The profiles of S176-5S/A, S183-5S/A and S193-5S/A each showed a minor peak around $\mathrm{m} / z$ 7990, suggesting the existence of an additional rhamnose residue in the peptide. Uniform glycosylation might be necessary for accurate attachment of rhamnose residues by glycosyltransferases.

\section{Motility of glycosylation-defective mutants}

The swimming and swarming motilities of each glycosylation-defective mutant were compared with those in the WT strain on $0.25 \%$ agar MMMF plates and $0.45 \%$ agar SWM plates, respectively. There was a small but significant difference in swimming motility among the WT and mutant strains (Fig. 2A). All mutant strains also showed reduced swarming motility (Fig. $2 \mathrm{~B}$ ). In particular, the S143-5S/A, S164-5S/A and S201-5S/A mutants were markedly impaired in swarming ability, but the S176-5S/ A, S183-5S/A and S193-5S/A mutants retained significant swarming motility. Because the glycosylation positions at S176 and S183 are located on the most external surface (Taguchi et al., 2006b) according to the predicted tertiary structure of flagellin, removal of glycans in these positions might have a greater effect than removal of those in other positions. This result was consistent with our previous finding that a single S176A- or S183A-substituted mutant exhibited reduced swarming motility compared with other single Ser/Ala mutants (Taguchi et al., 2006b). Quantitative analyses of swimming and swarming motilities are summarized in Table 2.

\section{Drop-collapsing test}

The production of biosurfactant in WT and mutant strains was investigated by the drop-collapsing test. The results indicated that there was no significant difference among the strains tested (see Supplementary Fig. S1, available with the online version of this paper).

\section{Detection of AHLs by TLC}

Quorum sensing regulates bacterial virulence factors in a cell-density-dependent manner. We previously reported 
(A)

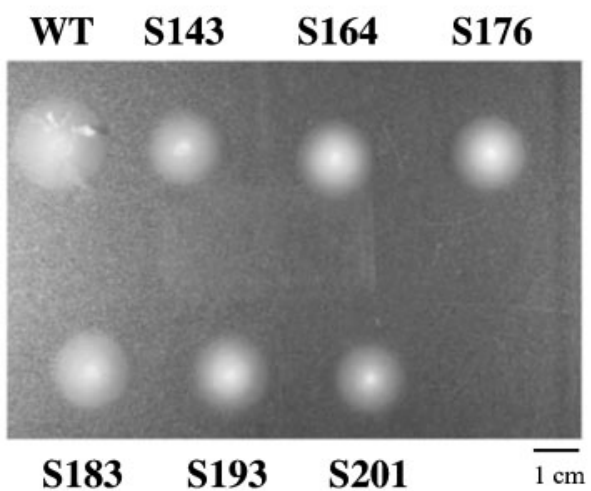

(B)

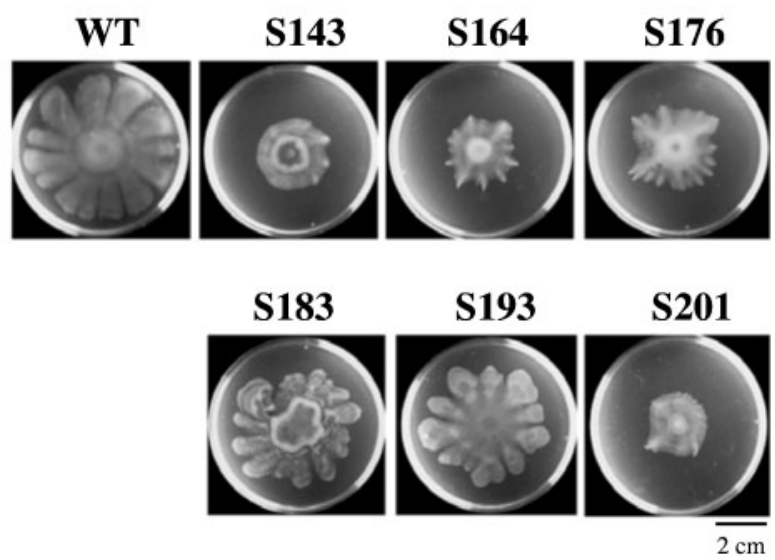

Fig. 2. Swimming $(A)$ and swarming $(B)$ assays. Aliquots $(3 \mu \mathrm{l})$ of each bacterial suspension $\left(6 \times 10^{8} \mathrm{c}\right.$.f.u. $\left.\mathrm{ml}^{-1}\right) \mathrm{were}$ inoculated on $0.25 \%$ agar MMMF plates for swimming assay or $0.45 \%$ agar SWM plates for swarming assay. Each plate was incubated for $48 \mathrm{~h}$ at $27{ }^{\circ} \mathrm{C}$. The photographs show representative results obtained from three independent experiments.

that P. syringae pv. tabaci 6605 produces HHL and OHHL as two major quorum-sensing signal molecules (Taguchi et al., 2006a). We also found that the flagellin-defective $\Delta$ fliC mutant is incapable of producing AHLs (Fig. 3). This result suggests that flagellar motility might be necessary for optimal production of AHLs. Therefore, TLC using $C$. violaceum CV026 as the AHL biosensor strain was performed to compare the ability of each glycosylationdefective mutant to produce AHLs. As shown in Fig. 3, the AHL production by the S176-5S/A, S183-5S/A and S1935S/A mutants was almost identical to that in the WT strain. In contrast, only a small amount of AHL was produced by the S143-5S/A and S201-5S/A mutants and $\Delta f g t 1$, a nonglycosylated mutant. This result may indicate a close relationship between AHL production and swarming motility. The quantitative analysis of AHL production is summarized in Table 2.

\section{Tolerance to antibiotics}

We previously reported that quorum sensing negatively regulated the production of EPS, and that AHL-deficient mutants $(\Delta p s y I$ and $\Delta o r f 3)$ were more resistant to antibiotic treatment (Taguchi et al., 2006a). Because some flagellin glycosylation-defective mutants have decreased ability to produce AHLs (Fig. 3), a growth inhibition test using chloramphenicol and spectinomycin was performed to compare susceptibility to these antibiotics. As shown in Fig. 4, $\Delta f l i C$ and $\Delta f g t 1$ mutants and the AHL-defective $\Delta p s y I$ mutant had markedly increased tolerance to these antibiotics. The S176-5S/ A, S183-5S/A and S193-5S/A mutants showed slightly increased antibiotic tolerance in the growth inhibition assay, whereas the S143-5S/A, S164-5S/A and S201-5S/A mutants showed higher tolerance to these antibiotics. These results suggest a possible correlation among quorum sensing via AHL production, swarming motility, and susceptibility to antibiotics.

Table 2. Quantitative analysis of motility and production of EPS and AHLs

Data shown are the means \pm SD of three independent replicates. Statistical significance is indicated by asterisks: ${ }^{\star} P<0.05,{ }^{* \star} P<0.01$.

\begin{tabular}{|c|c|c|c|c|c|}
\hline \multirow[t]{2}{*}{ Strains } & \multicolumn{2}{|c|}{ Motility } & \multirow[t]{2}{*}{ EPS $\left[A_{490}(m g \text { protein })^{-1}\right]$} & \multicolumn{2}{|c|}{ AHLs [ng $\left.(\mathrm{ml} \text { medium })^{-1}\right]$} \\
\hline & Swim $(\mathrm{cm})$ & Swarm $(\mathrm{cm})$ & & HHL & OHHL \\
\hline WT & $2.39 \pm 0.063$ & $6.67 \pm 0.15$ & $0.905 \pm 0.187$ & $97.6 \pm 12.6$ & $76.4 \pm 2.11$ \\
\hline $143 S-5 S / A$ & $1.83 \pm 0.050^{\star *}$ & $1.80 \pm 0.20^{\star *}$ & $0.701 \pm 0.239$ & $17.3 \pm 0.95^{\star *}$ & $11.0 \pm 2.07^{\star *}$ \\
\hline $164 S-5 S / A$ & $1.85 \pm 0.100^{\star}$ & $1.80 \pm 0.12^{\star *}$ & $0.567 \pm 0.045^{\star}$ & $16.7 \pm 2.40^{\star *}$ & $11.2 \pm 2.63^{\star \star}$ \\
\hline $176 \mathrm{~S}-5 \mathrm{~S} / \mathrm{A}$ & $1.88 \pm 0.130^{\star}$ & $3.92 \pm 0.25^{\star *}$ & $0.646 \pm 0.278$ & $48.0 \pm 5.55^{\star}$ & $39.6 \pm 2.93^{* *}$ \\
\hline 183S-5S/A & $1.86 \pm 0.110^{*}$ & $5.37 \pm 0.11^{* *}$ & $0.739 \pm 0.297$ & $76.5 \pm 5.71$ & $37.5 \pm 2.93^{\star *}$ \\
\hline 193S-5S/A & $1.85 \pm 0.129^{*}$ & $5.07 \pm 0.11^{\star *}$ & $0.584 \pm 0.097$ & $73.2 \pm 9.63$ & $39.9 \pm 3.96^{*}$ \\
\hline 201S-5S/A & $1.83 \pm 0.043^{\star *}$ & $1.83 \pm 0.25^{\star *}$ & $0.627 \pm 0.178$ & $9.76 \pm 2.40^{\star *}$ & $8.76 \pm 0.54^{\star \star}$ \\
\hline
\end{tabular}




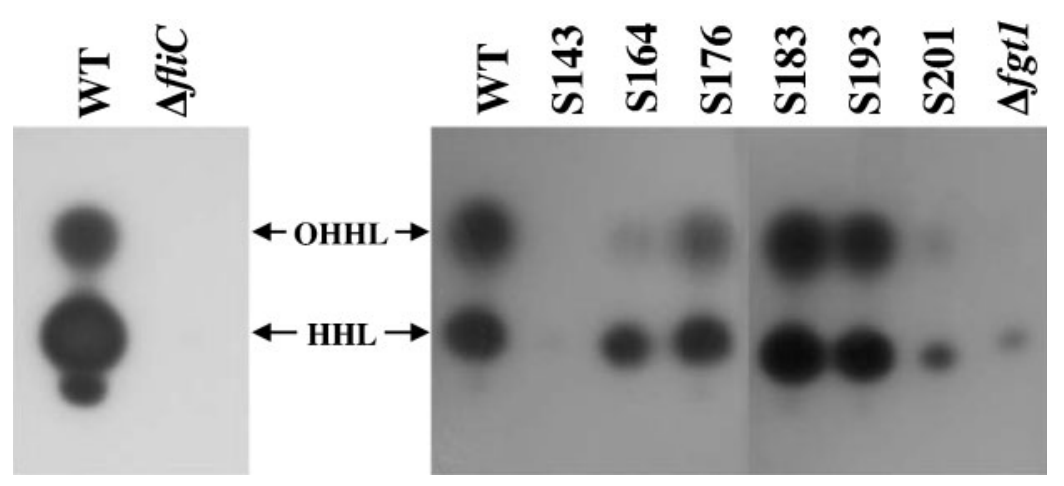

Fig. 3. Detection of AHLs using C. violaceum CV026 as biosensor strain. Ethyl acetate extracts from each strain were developed on a $\mathrm{C}_{18}$ reverse-phase TLC plate. The photographs show representative results obtained from three independent experiments.

\section{EPS production}

The production of EPS was investigated in WT and mutant strains (Table 2). No significant difference was found in the amounts of EPS produced by the WT and glycosylation-defective mutant strains, except mutant S164-5S/A.

\section{Virulence of mutants on tobacco leaves}

To compare the abilities of the WT and each glycosylation-defective mutant to cause disease on tobacco leaves, dip-inoculation of each bacterium at $6 \times 10^{8}$ c.f.u. $\mathrm{ml}^{-1}$ was carried out. The results showed that virulence to host tobacco plants was significantly attenuated in all of the mutants (Fig. 5A). The leaves inoculated with the S1765S/A and S183-5S/A mutants exhibited slight chlorosis, suggesting that these mutants retain some virulence. The populations of the WT strain and each mutant were examined 3 and 6 days after inoculation. As shown in Fig. 5(B), all of the mutants had less growth than the WT strain, especially mutants S143-5S/A, S164-5S/A and S201-5S/A.

\section{Expression of genes related to drug resistance}

Because antibiotic tolerance is related to active multidrug efflux pumps, expression of two genes related to drug resistance was investigated by RT-PCR (Fig. 6). Among the active drug efflux pumps, transporters of the resistancenodulation-division family (RND superfamily) have a predominant role in Gram-negative bacteria (Nikaido, 2009). The RND multidrug efflux pumps are associated with two other classes of proteins, outer-membrane proteins such as TolC in E. coli and membrane fusion proteins such as AcrA in E. coli. Significant expression of the genes encoding MexF, a member of the RND pump family, and TolC were observed in $\Delta f l i C, \Delta f g t 1$ and $\Delta p s y I$ mutant strains but expression was not detected in the WT strain. The mexF and tolC genes belong to the same operon in $P$. aeruginosa and $P$. syringae.

\section{DISCUSSION}

Previously, we determined the glycan structure of flagellin protein at serine 201 using a digested peptide derived from
(A)

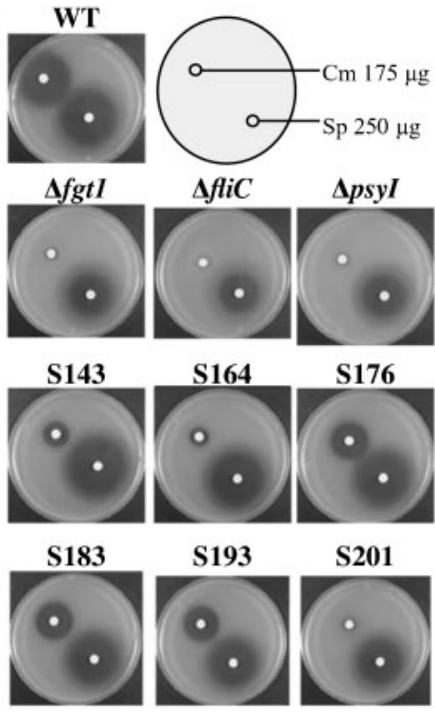

(B)

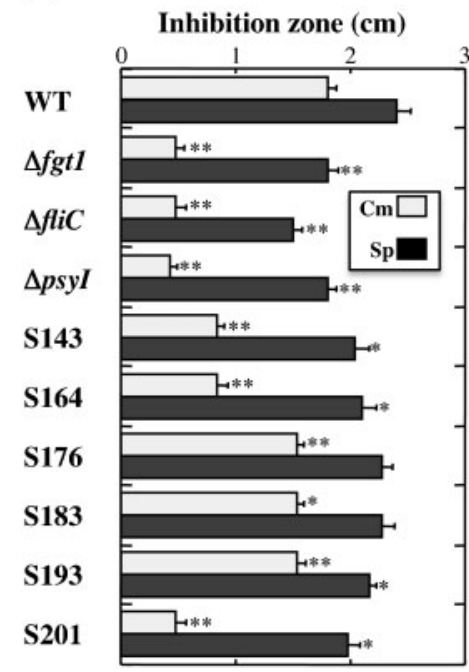

Fig. 4. Antibiotic tolerance tests. (A) Paper discs containing $10 \mu \mathrm{l}$ of antibiotic solution $\left(17.5 \mu \mathrm{g}\right.$ chloramphenicol $\mu \mathrm{l}^{-1}$ and $25 \mu \mathrm{g}$ spectinomycin $\mu \mathrm{I}^{-1}$ ) were placed on each bacterium-containing KB plate. Photographs were taken after $24 \mathrm{~h}$ at $27^{\circ} \mathrm{C}$. (B) The diameter of the growth-inhibition zone was measured after incubation for $24 \mathrm{~h}$ at $27^{\circ} \mathrm{C}$. Data shown are the means \pm SD of three independent experiments. Asterisks indicate a significant difference from the the WT in a $t$ test $\left({ }^{\star} P<0.05,{ }^{\star \star} P<0.01\right)$. 


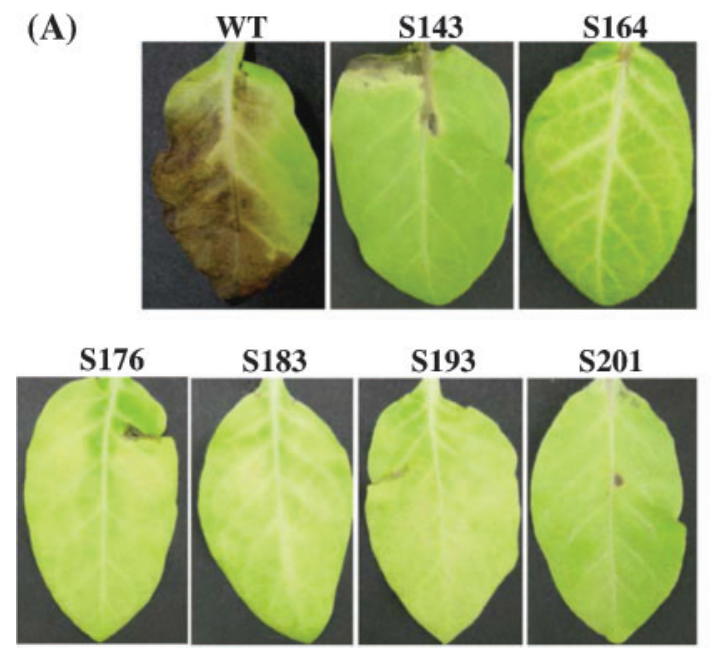

(B)

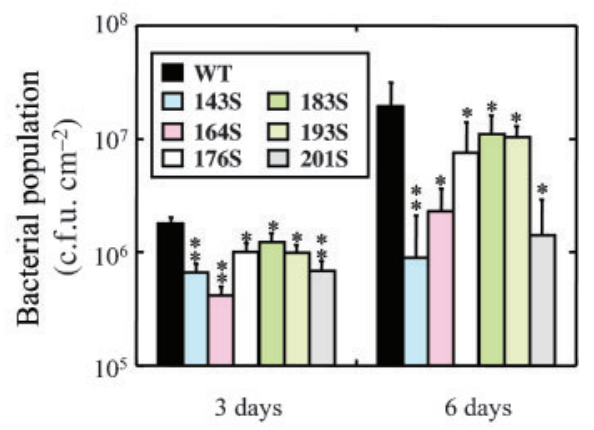

Fig. 5. Virulence assays. (A) Tobacco leaves were dip-inoculated with each bacterium at $6 \times 10^{8}$ c.f.u. $\mathrm{ml}^{-1}$ for $20 \mathrm{~min}^{\mathrm{and}}$ incubated at $23^{\circ} \mathrm{C}$. Photographs were taken 10 days after inoculation. Representative results from three independent experiments are shown. (B) Bacterial growth in tobacco leaf discs was calculated at 3 and 6 days post-inoculation. The bars represent means \pm SD for three experiments. Asterisks indicate a significant difference from the WT in a $t$-test $\left({ }^{\star} P<0.05\right.$, $\left.{ }^{\star *} P<0.01\right)$.

flagellin of the WT strain (Takeuchi et al., 2007), by means of sugar composition analysis, mass spectrometry, and ${ }^{1} \mathrm{H}$ and ${ }^{13} \mathrm{C}$ NMR spectroscopy. Digestion of flagellin by Asp-N endoproteinase generated three fractions (D200-A211, D168-T187 and D139-F167) and the D200-A211 fraction had a single glycosylation site at S201; therefore, we succeeded in the structural analysis of this glycan. However, we had no suitable peptidase to target peptides containing other single glycosylation sites for detailed structural analysis. In this study, site-directed Ser/Ala substitutions were constructed: in each, a single glycosylated serine remained, but Ser was replaced by an Ala residue in the other five glycosylated sites to obtain mutant flagellins

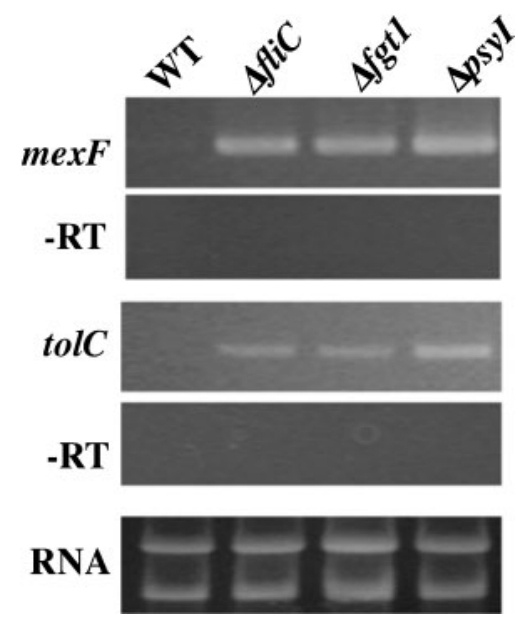

Fig. 6. Expression of $m e x F$ and to/C genes in each strain. that possessed only a single glycan. Flagellin proteins prepared from these mutants are convenient tools for structural analysis of glycans. Although we did not generate complemented strains for each mutant, the multiple mutant strains showed similar phenotypes. Therefore, spontaneous mutations probably did not occur during the mutagenesis experiment, but this possibility can not be excluded.

Swarming motility has been reported to be linked to bacterial virulence and is enhanced by addition of biosurfactants, which are secreted by several bacteria to reduce surface tension (Brint \& Ohman, 1995; Taguchi et al., 2006b). Although the S143-5S/A, S164-5S/A and S201-5S/A mutants had reduced swarming ability, the production of the biosurfactant by these mutants showed no significant difference compared with the WT strain as assayed by the drop-collapsing test (Supplementary Fig. S1). We previously demonstrated that flagella from glycosylation-defective mutants ( $\Delta f g t 1$ and all six glycosylated Ser/Ala-substituted mutants) displayed irregular entanglements of filaments and many thick flagellar bundles (Taguchi et al., 2008). Because flagella from glycosylation-defective mutants might have a different surface charge that reduces the hydrophilic properties, the swarming motility would be impaired. Flagellin glycosylation, especially at positions S176 and S183, contributed to smooth motility, and it was confirmed that glycosylation of the most surface-exposed positions plays an indispensable role in the swarming motility of $P$. syringae pv. tabaci 6605 .

Many studies have shown that quorum sensing plays an important role in regulation of the expression of many virulence factors in Gram-negative bacteria (Daniels et al., 2004). Our previous study demonstrated that orf3 located 
between $f g t 2$ and $f l i C$ plays no role in post-translational modification, but a $\Delta$ orf3 mutant nearly lost the ability to produce AHLs, indicating that Orf3 is involved in production of AHLs as quorum-sensing signal molecules (Taguchi et al., 2006b). The orf3 product is highly homologous to the 3-oxoacyl-(acyl carrier protein) synthase III of E. coli and Pseudomonas putida strain KT2440 in the fatty acid elongation cycle (Nelson et al., 2002; Takeuchi et al., 2003). Although the reason why a gene concerned with quorum sensing is present in the glycosylation island of the flagellar gene cluster is still obscure, quorum sensing via Orf3 should be correlated with flagellum expression. As shown in Fig. 3, the amounts of AHL produced by the $\Delta f g t 1, \mathrm{~S} 143-5 \mathrm{~S} / \mathrm{A}$ and S201-5S/A mutants were significantly reduced, and these mutants showed lower swarming ability. We observed that swimming- and swarming-defective mutants, such as $\Delta f l i C$, had lost the ability to produce AHLs (Fig. 3). This result led us to speculate on a possible relationship between the synthesis of AHLs and flagellum-dependent swarming motility. To elucidate this hypothesis, we will investigate the relationship between the expression of genes required for flagellin glycosylation, such as $f l i C$ and $f g t 1$, and genes required for AHL biosynthesis, such as orf 3 and psyI.

It was reported that a mutant of $P$. syringae deficient in EPS production had enhanced sensitivity to $\mathrm{H}_{2} \mathrm{O}_{2}$ (Keith \& Bender, 1999; Daniels et al., 2004; Quinones et al., 2005), and the $\Delta$ orf 3 mutant of $P$. syringae pv. tabaci 6605 had enhanced tolerance to $\mathrm{H}_{2} \mathrm{O}_{2}$ and antibiotics due to the overexpression of EPS (Taguchi et al., 2006a). In Vibrio cholerae $\mathrm{O} 139$ strain MO10, a relationship between the flagellum-dependent EPS signalling cascade and virulence was demonstrated by the result that disruption of the system of flagellar synthesis elevated EPS expression (Lauriano et al., 2004). In P. syringae pv. tabaci 6605, although the S143-5S/A, S164-5S/A and S201-5S/A mutants were highly tolerant of antibiotics (Fig. 4), the amounts of EPS produced by these glycosylation-defective mutants, except S164-5S/A, were similar to that in the WT strain (Table 2). Therefore, the flagellum may affect tolerance to antibiotics and virulence via EPS-independent pathways in this bacterium.

The mechanisms of increased tolerance to antibiotics in the AHL production-defective mutants $\Delta f g t 1, \Delta f l i C, \Delta p s y I$, S143-5S/A, S164-5S/A and S201-5S/A are not known. Two mechanisms for acquiring multidrug resistance in bacteria have been reported (Nikaido, 2009). One is the accumulation of multiple genes coding for resistance to drugs, and the second is increased expression of genes related to multidrug efflux pumps. We found that the expression of mexF and tolC, which are RND multidrug efflux pump related genes, was significantly elevated in motilitydefective mutants and also in AHL synthesis-defective mutants (Fig. 6). In $P$. aeruginosa, mutation of genes encoding the efflux protein MexI and the porin OpmD resulted in the inability to produce OHHL and 2-heptyl-3hydroxy-4(1H)-quinolone (PQS) and a marked reduction in $\mathrm{N}$-butanoyl-L-homoserine lactone levels (Aendekerk et al., 2005). These mutants showed enhanced resistance to several classes of antibiotics compared with the WT strain. Aendekerk et al. (2005) further demonstrated that exogenous PQS restored AHL production as well as antibiotic susceptibility, indicating that the MexGHIOpmD multidrug efflux pump is required for secretion of PQS and control of antibiotic susceptibility and virulence via PQS-dependent cell-to-cell communication. However, because OHHL was shown to be freely diffused through Vibrio fischeri cells (Kaplan \& Greenberg, 1985), an active pump is not necessary for transport of this molecule. Although quorum-sensing molecules, including PQS, positively regulate antibiotic resistance in $P$. aeruginosa, an AHL-dependent quorum-sensing system might control antibiotic susceptibility by negative regulation of the mexEF-tolC gene cluster in P. syringae pv. tabaci 6605. Further characterization of these genes using respective mutant strains should elucidate the mechanism of flagellar motility-mediated quorum sensing and/or multidrug resistance in $P$. syringae pv. tabaci 6605 . The findings of this study suggest the possibility of controlling virulence by using inhibitors of flagellum-dependent motility, making it possible to reduce the use of bactericides in agricultural fields.

\section{ACKNOWLEDGEMENTS}

We thank the Leaf Tobacco Research Laboratory of Japan Tobacco Inc. for providing P. syringae pv. tabaci 6605. This work was supported in part by the Program for Promotion of Basic Research Activities for Innovative Bioscience (PROBRAIN).

\section{REFERENCES}

Aendekerk, S., Diggle, S. P., Song, Z., Høiby, N., Cornelis, P., Williams, P. \& Cámara, M. (2005). The MexGHI-OpmD multidrug efflux pump controls growth, antibiotic susceptibility and virulence in Pseudomonas aeruginosa via 4-quinolone-dependent cell-to-cell communication. Microbiology 151, 1113-1125.

Brint, J. M. \& Ohman, D. E. (1995). Synthesis of multiple exoproducts in Pseudomonas aeruginosa is under the control of RhlR-RhlI, another set of regulators in strain PAO1 with homology to the autoinducerresponsive LuxR-LuxI family. J Bacteriol 177, 7155-7163.

Daniels, R., Vanderleyden, J. \& Michiels, J. (2004). Quorum sensing and swarming migration in bacteria. FEMS Microbiol Rev 28, 261289.

Higashi, K., Ishiga, Y., Inagaki, Y., Toyoda, K., Shiraishi, T. \& Ichinose, Y. (2008). Modulation of defense signal transduction by flagellin-induced WRKY41 transcription factor in Arabidopsis thaliana. Mol Genet Genomics 279, 303-312.

Hodge, J. E. \& Hofreiter, B. T. (1962). Determination of reducing sugars and carbohydrates. In Methods in Carbohydrate Chemistry, vol. 1, pp. 380-394. Edited by R. L. Whistler \& M. L. Wolfrom. New York: Academic Press.

Ichinose, Y., Shimizu, R., Ikeda, Y., Taguchi, F., Marutani, M., Mukaihara, T., Inagaki, Y., Toyoda, K. \& Shiraishi, T. (2003). Need for flagella for complete virulence of Pseudomonas syringae pv. tabaci: 
genetic analysis with flagella-defective mutants $\Delta$ fliC and $\Delta$ fliD in host tobacco plants. J Gen Plant Pathol 69, 244-249.

Kaplan, H. B. \& Greenberg, E. P. (1985). Diffusion of autoinducer is involved in regulation of the Vibrio fischeri luminescence system. J Bacteriol 163, 1210-1214.

Keith, L. M. \& Bender, C. L. (1999). AlgT $\left(\sigma^{22}\right)$ controls alginate production and tolerance to environmental stress in Pseudomonas syringae. J Bacteriol 181, 7176-7184.

Kinscherf, T. G. \& Willis, D. K. (1999). Swarming by Pseudomonas syringae $\mathrm{B} 728$ a requires gacS (lemA) and gacA but not the acylhomoserine lactone biosynthetic gene ahlI. J Bacteriol 181, 4133-4136.

Lauriano, C. M., Ghosh, C., Correa, N. E. \& Klose, K. E. (2004). The sodium-driven flagellar motor controls exopolysaccharide expression in Vibrio cholerae. J Bacteriol 186, 4864-4874.

McClean, K. H., Winson, M. K., Fish, L., Taylor, A., Chhabra, S. R., Camara, M., Daykin, M., Lamb, J. H., Swift, S. B. \& other authors (1997). Quorum sensing and Chromobacterium violaceum: exploitation of violacein production and inhibition for the detection of $\mathrm{N}$ acylhomoserine lactones. Microbiology 143, 3703-3711.

Nelson, K. E., Weinel, C., Paulsen, I. T., Dodson, R. J., Hilbert, H., Martins dos Santos, V. A., Fouts, D. E., Gill, S. R., Pop, M. \& other authors (2002). Complete genome sequence and comparative analysis of the metabolically versatile Pseudomonas putida KT2440. Environ Microbiol 4, 799-808.

Nikaido, H. (2009). Multidrug resistance in bacteria. Annu Rev Biochem 78, 119-146.

Quinones, B., Dulla, G. \& Lindow, S. E. (2005). Quorum sensing regulates exopolysaccharide production, motility, and virulence in Pseudomonas syringae. Mol Plant Microbe Interact 18, 682-693.

Schäfer, A., Tauch, A., Jäger, W., Kalinowski, J., Thierbach, G. \& Pühler, A. (1994). Small mobilizable multi-purpose cloning vectors derived from the Escherichia coli plasmids pK18 and pK19: selection of defined deletions in the chromosome of Corynebacterium glutamicum. Gene 145, 69-73.

Shaw, P. D., Ping, G., Daly, S. L., Cha, C., Cronan, J. E., Jr, Rinehart, K. L. \& Farrand, S. K. (1997). Detecting and characterizing $\mathrm{N}$-acylhomoserine lactone signal molecule by thin-layer chromatography. Proc Natl Acad Sci U S A 94, 6036-6041.
Shimizu, R., Taguchi, F., Marutani, M., Mukaihara, T., Inagaki, Y., Toyoda, K., Shiraishi, T. \& Ichinose, Y. (2003). The $\Delta f l i D$ mutant of Pseudomonas syringae pv. tabaci, which secretes flagellin monomers, induces a strong hypersensitive reaction (HR) in non-host tomato cells. Mol Genet Genomics 269, 21-30.

Taguchi, F., Shimizu, R., Inagaki, Y., Toyoda, K., Shiraishi, T. \& Ichinose, Y. (2003a). Post-translational modification of flagellin determines the specificity of HR induction. Plant Cell Physiol 44, 342349.

Taguchi, F., Shimizu, R., Nakajima, R., Toyoda, K., Shiraishi, T. \& Ichinose, Y. (2003b). Differential effects of flagellins from Pseudomonas syringae pv. tabaci, tomato and glycinea on plant defense response. Plant Physiol Biochem 41, 165-174.

Taguchi, F., Takeuchi, K., Katoh, E., Murata, K., Suzuki, T., Marutani, M., Kawasaki, T., Eguchi, M., Katoh, S. \& other authors (2006a). Identification of glycosylation genes and glycosylated amino acids of flagellin in Pseudomonas syringae pv. tabaci. Cell Microbiol 8, 923-938.

Taguchi, F., Ogawa, Y., Takeuchi, K., Suzuki, T., Toyoda, K., Shiraishi, T. \& Ichinose, Y. (2006b). A homologue of the 3oxoacyl-(acyl carrier protein) synthase III gene located in the glycosylation island of Pseudomonas syringae pv. tabaci regulates virulence factors via $\mathrm{N}$-acyl homoserine lactone and fatty acid synthesis. J Bacteriol 188, 8376-8384.

Taguchi, F., Shibata, S., Suzuki, T., Ogawa, Y., Aizawa, S., Takeuchi, K. \& Ichinose, Y. (2008). Effects of glycosylation on swimming ability and flagellar polymorphic transformation in Pseudomonas syringae pv. tabaci 6605. J Bacteriol 190, 764-768.

Takeuchi, K., Taguchi, F., Inagaki, Y., Toyoda, K., Shiraishi, T. \& Ichinose, Y. (2003). Flagellin glycosylation island in Pseudomonas syringae pv. glycinea and its role in host specificity. J Bacteriol 185, 6658-6665.

Takeuchi, K., Ono, H., Yoshida, M., Ishii, T., Katoh, E., Taguchi, F., Miki, R., Murata, K., Kaku, H. \& Ichinose, Y. (2007). Flagellin glycans from two pathovars of Pseudomonas syringae contain rhamnose in $\mathrm{D}$ and $\mathrm{L}$ configurations in different ratios and modified 4-amino-4,6dideoxyglucose. J Bacteriol 189, 6945-6956.

Edited by: I. K. Toth 